\title{
A Preliminary Analysis of a Home-Based Stroke Rehabilitation Program in Windsor, Ontario
}

\author{
Jennifer Voth, Jason Petro, Michael Mallender, Sonja Bridgen, Sara Mannan, \\ Marla Jackson, Nathania R. Liem
}

\begin{abstract}
Community stroke rehabilitation (CSR) is an effective program for survivors to recover at home supported by a multidisciplinary team. A home-based, specialized CSR program was delivered in Windsor, Ontario, to stroke patients who faced barriers to accessing outpatient services following inpatient rehabilitation. Preliminary results show program patients made significant functional improvements from baseline to program discharge. A subgroup analysis revealed that, after adjusting for age and resource intensity, moderate to severe stroke patients made greater functional gains compared to mild stroke patients. The individualized focus of CSR delivered in the home provides an effective model of rehabilitation for continued stroke care in the community.
\end{abstract}

RÉSUMÉ: Analyse préliminaire d'un programme de réadaptation à domicile pour des patients ontariens victimes d'un AVC. La réadaptation en milieu communautaire demeure un programme efficace dans le cas de patients victimes d'un AVC souhaitant se rétablir à domicile et bénéficier de l'appui d'une équipe multidisciplinaire. Un tel programme a été offert à des patients de Windsor (Ontario) ayant éprouvé des difficultés à obtenir des services ambulatoires (outpatient services) consécutifs à des séances de réadaptation en milieu hospitalier. Nos résultats préliminaires montrent que les patients bénéficiaires d'un tel programme ont connu une progression importante de leurs capacités fonctionnelles entre le début et la fin des services leur étant offerts. Après correction pour tenir compte de l'âge et de l'intensité d'utilisation des ressources, une analyse par sous-groupes a aussi révélé que les patients victimes d'AVC modérés à graves ont davantage amélioré leur état fonctionnel si on les compare à des patients victimes d'AVC légers. Bref, l'approche individualisée de ce programme constitue un modèle efficace de réadaptation dans le cas de soins post-AVC offerts dans la communauté.

Keywords: Stroke rehabilitation, Health services research

doi:10.1017/cjn.2019.26

Can J Neurol Sci. 2019; 46: 464-467

Canadian stroke best practice guidelines indicate that stroke survivors should receive outpatient or community-based rehabilitation services within 72 hours following hospital discharge, when it is deemed necessary. ${ }^{1}$ However, access to outpatient rehabilitation services may be limited for certain patients due to factors such as geography, transportation, or the level of functional impairments, as it requires the patient to travel from home to an outpatient facility. ${ }^{2}$ Furthermore, Ontario stroke survivors wait a median of 10 days for outpatient occupational therapy (OT) services, and 21 days for outpatient physiotherapy (PT) services depending on the region, ${ }^{3}$ which can result in a loss of functional gains made during inpatient rehabilitation. ${ }^{1}$

Stroke severity can also play a key role in access to rehabilitative services. ${ }^{4}$ Best practice recommends that all individuals with moderate and severe impairment due to stroke have equitable access to inpatient rehabilitation; however, in practice, access can often be limited due to greater severity being associated with poorer prognosis and reduced capacity to recover functional independence compared to those who have experienced less severe deficits. ${ }^{5}$ However, research shows that moderate and severe stroke patients can greatly benefit from inpatient rehabilitation services, resulting in decreased mortality rates and increased likelihood of discharge home. ${ }^{5}$ Pereira et al. ${ }^{5}$ suggest that following inpatient rehabilitation, particularly in the absence of a caregiver, additional community support is essential to facilitating patients with greater disability due to stroke returning home; however, guidance on where and how that support should be delivered is currently limited.

The need for community-based stroke rehabilitation services in the Windsor Essex County (WEC) region in Ontario, Canada, for individuals living with stroke is well documented. Thirty-four percent of WEC residents have difficulty in accessing health services, with a lack of transportation identified as the primary barrier. ${ }^{6}$ This is notably prevalent in the county regions outside of Windsor, as these residents do not have access to reliable or accessible public transportation. ${ }^{6}$ Moreover, stroke patients in the WEC region discharged from an acute care or inpatient rehabilitation stay receive on average 5.4 homecare

From the Research and Evaluation Services Department, Hôtel-Dieu Grace Healthcare, Windsor, Ontario, Canada (JV, MM, SB, MJ); Ambulatory Services Department, HôtelDieu Grace Healthcare, Windsor, Ontario, Canada (JP); Department of Rehabilitative Care, Hôtel-Dieu Grace Healthcare, Windsor, Ontario, Canada (NRL); Department of Human Kinetics, University of Windsor, Windsor, Ontario, Canada (MM); Quality \& Performance, London Health Sciences Centre, London, Ontario, Canada (SM); Schulich School of Medicine \& Dentistry, Western University, London, Ontario, Canada (NRL)

Received August 28, 2018. Final Revisions Submitted February 6, 2019. Date of Acceptance February 26, 2019.

Correspondence to: Jennifer Voth, Research \& Evaluation Services Department, HôtelDieu Grace Healthcare, 2624-1453 Prince Rd., Windsor, ON N9C 3Z4, Canada. Email: jennifer.voth@hdgh.org 
visits, well below the provincial benchmark of $12.4,{ }^{7}$ leaving a large gap in post-hospital rehabilitation care.

A recent community stroke rehabilitation (CSR) model of care involving comprehensive, multidisciplinary, specialized stroke services provided at a patient's home has emerged as an effective and viable alternative to traditional outpatient rehabilitation. ${ }^{8,9}$ Specifically, home-based stroke rehabilitation programs are associated with decreased length of stay and readmissions, ${ }^{2}$ reduced caregiver burden, decreased anxiety and depression, and improved functional ability that is sustained up to six-month postdischarge. ${ }^{8}$ A CSR program delivered in London, Ontario, was shown to be an accessible, timely, and effective alternative to hospital-based outpatient services that eliminates barriers to postinpatient rehabilitation. ${ }^{8,9}$ However, home-based CSR in Canada is still in its infancy; therefore, studies examining the effectiveness of these programs in supporting stroke patients' continued recovery in the community following inpatient rehabilitation services and whether different subgroups of stroke patients benefit from this approach are warranted. ${ }^{10}$ This brief communication examines preliminary findings from the CSR program delivered by Hôtel-Dieu Grace Healthcare (HDGH) in Windsor, Ontario, and provides evidence for the benefits of delivering a CSR model as an approach to transition individuals with a range of functional deficits home successfully following inpatient rehabilitation.

A home-based CSR program developed in consultation with the South West LHIN CSR team ${ }^{8}$ was delivered by HDGH, a tertiary hospital in Windsor, Ontario, Canada, to stroke patients following an inpatient rehabilitation stay. Eligibility criteria to the HDGH CSR program included: (a) the individual faced significant barriers (i.e., lack of transportation, low functionality) to regular attendance of outpatient rehabilitation; (b) the patient's projected wait time for intake to outpatient services was deemed unacceptably long for their specific needs; and (c) the patient's rehabilitation goals were deemed realistic for a home-based program. Patients were additionally referred to the CSR program based upon clinical recommendation from a consulting physiatrist. The CSR team included one physiotherapist, one occupational therapist, one speech language pathologist, one registered nurse, one social worker, and three certified rehabilitation assistants. The number of discipline-specific visits each patient received was dependent on their individual needs and rehabilitation goals. Targeted length of service for program patients was set at 12 weeks; however, prior to completing the program, 22 CSR patients were bridged to outpatient rehabilitation once their physical function improved to enable the transition.

The Functional Independent Measure $\left(\mathrm{FIM}^{\circledR}\right)$ was utilized to assess patient functional abilities at admission upon intake into the CSR program and again at discharge. ${ }^{11}$ The FIM $^{\circledR}$ has previously been utilized as a valid and reliable method to evaluate CSR program outcomes. ${ }^{8}$ FIM $^{\circledR}$ scores were collected by CSR staff upon the first (admission) and last (discharge) visits, and entered into a program database by a CSR team member. Differences in patient's length of service resulted in variable time between admission and discharge FIM $^{\circledR}$ assessment. Stroke severity was defined based on individuals' FIM $^{\circledR}$ score at admission to the program ${ }^{12}\left(\right.$ mild stroke $=$ FIM $^{\circledR}>80$; moderate stroke = FIM $^{\circledR} 40-80$; severe stroke $=$ FIM $^{\circledR}<40$ ). After completing their inpatient rehabilitation stay, few patients had severe functional deficits upon admission to the CSR program and were therefore grouped together with the moderate stroke group. Data were collected from August 2016 to February 2018. Differences between patients who completed the CSR program and those who were bridged to outpatient rehabilitation, and between mild and moderate/severe stroke patients on demographic characteristics, resource intensity, length of service, and functional outcomes were examined using independent samples $t$-tests or MannWhitney $U$ tests and chi-square or Fisher's exact tests, where appropriate. Paired samples' $t$-tests were used to assess changes in functional outcomes between admission and discharge for patients who completed the full CSR program. A repeated measures analysis of covariance (RM ANCOVA) was further applied to examine differences in functionality from admission to discharge between stroke severity subgroups, adjusting for age and resource intensity. This study was approved by the University of Windsor Research Ethics Board.

Between August 2016 to February 2018, 95 stroke patients were discharged from the CSR program. Of these patients, 73 were discharged after completing the full CSR program and 22 patients were discharged early to facility-based outpatient rehabilitation once their physical function improved to enable the transition. Table 1 describes patient and program characteristics for this group relative to patients who completed the CSR program. In particular, patients that were bridged to the outpatient program were significantly younger, more likely male, and had greater functional ability at the outset of the CSR program compared to patients who had completed the full program. However, given the focus on evaluating the full in-home CSR program, patients who were transitioned to outpatient services were excluded from further analysis.

The mean age of patients who completed the program was 74 years old. These patients were enrolled in the home-based CSR program for an average of 76.5 days and received an average of 3.6 visits per week. The majority of patients (73\%) who completed the program were experiencing mild neurological impairment upon admission, whereas a smaller subgroup (27\%) had either moderate or severe disability due to stroke. A complete breakdown of patient and program characteristics stratified by stroke severity can be found in Table 2 .

Overall, patients who completed the program showed a statistically significant increase in functional ability (FIM change $=12.9$ points; $p=0.000$ ) from admission (88.8) to discharge (101.7). When stratified by stroke severity, both the mild $(p=0.000)$ and moderate/severe $(p=0.000)$ stroke patients demonstrated significant functional improvement post-discharge from CSR and no significant differences in resource intensity between subgroups were observed. A significant interaction between stroke severity and functional improvement from admission to discharge was observed ( $p=0.020, \eta^{2}=0.08$; Figure 1). Specifically, the moderate/ severe stroke subgroup experienced on average greater functional gains (FIM change $=16.2$ ) compared to the mild stroke subgroup (FIM change $=10.4$ ) during the CSR program, after adjusting for age and resource intensity.

These preliminary results provide further evidence that homebased CSR is an effective approach for supporting individuals living with stroke to continue making functional improvement in the community following an inpatient rehabilitation stay. These findings are consistent with outcomes demonstrated by other CSR programs operating in neighboring regions. ${ }^{8}$ Notably, results from this analysis appear to indicate that home-based CSR may be beneficial for successfully transitioning home individuals with 


\section{Table 1: Patient and program characteristics for CSR program patients discharged early to outpatient services compared to patients who completed the full CSR program}

\begin{tabular}{|c|c|c|c|}
\hline & $\begin{array}{l}\text { Stroke patients } \\
\text { who completed } \\
\text { the full CSR } \\
\text { program } \\
(n=73)\end{array}$ & $\begin{array}{l}\text { Stroke patients } \\
\text { discharged } \\
\text { early to } \\
\text { outpatient } \\
\text { services }(n=22)\end{array}$ & $p$-Value \\
\hline Age, mean (SD) & $74.2(12.0)$ & $63.9(12.83)$ & $0.001^{\mathrm{a}}$ \\
\hline Age, median (IQR) & $75(68.3-82.8)$ & $65(58-74)$ & $0.001^{\mathrm{b}}$ \\
\hline \multicolumn{4}{|l|}{ Sex, $n(\%)$} \\
\hline Male & $38(48 \%)$ & $18(82 \%)$ & $0.010^{\mathrm{c}}$ \\
\hline Female & $35(52 \%)$ & $4(18 \%)$ & \\
\hline \multicolumn{4}{|l|}{ Residence, $n(\%)$} \\
\hline Windsor & $50(69 \%)$ & $13(59 \%)$ & $0.292^{\mathrm{c}}$ \\
\hline County & $22(31 \%)$ & $9(41 \%)$ & \\
\hline $\begin{array}{l}\text { FIM efficiency }{ }^{\mathrm{d}} \text { in inpatient } \\
\text { rehabilitation, mean (SD) }\end{array}$ & $1.04(0.76)$ & $1.2(0.72)$ & $0.415^{\mathrm{a}}$ \\
\hline \multicolumn{4}{|l|}{$\begin{array}{l}\text { Number of CRS visits, } \\
\text { mean (SD) }\end{array}$} \\
\hline Total & $39.0(15.16)$ & $28.1(16.92)$ & $0.004^{\mathrm{a}}$ \\
\hline Physiotherapist & $7.0(4.31)$ & $5.23(3.96)$ & $0.093^{\mathrm{a}}$ \\
\hline Occupational therapist & $7.0(2.99)$ & $5.6(3.80)$ & $0.06^{\mathrm{a}}$ \\
\hline $\begin{array}{l}\text { Speech language } \\
\text { pathologist }\end{array}$ & $6.5(7.44)$ & $5.1(6.66)$ & $0.412^{\mathrm{a}}$ \\
\hline Certified Rehab. assistant & $14.1(6.83)$ & $9.8(5.55)$ & $0.009^{a}$ \\
\hline Registered nurse & $2.01(1.11)$ & $1.3(0.99)$ & $0.006^{a}$ \\
\hline Social worker & $2.4(1.30)$ & $2.2(0.97)$ & $0.512^{a}$ \\
\hline $\begin{array}{l}\text { Length of service (days), } \\
\text { mean (SD) }\end{array}$ & $76.5(19.91)$ & $51.7(18.58)$ & $<0.001^{a}$ \\
\hline $\begin{array}{l}\text { Resource intensity (visits } \\
\text { per week), mean (SD) }\end{array}$ & $3.6(1.31)$ & $3.75(1.72)$ & $0.712^{a}$ \\
\hline Admission FIM, mean (SD) & $88.8(22.48)$ & $99.4(16.01)$ & $0.045^{a}$ \\
\hline Discharge FIM, mean (SD) & $101.7(21.66)$ & $107.2(14.61)$ & $0.206^{a}$ \\
\hline $\begin{array}{l}\text { FIM efficiency }{ }^{\mathrm{d}} \text { in CSR } \\
\text { program, mean (SD) }\end{array}$ & $0.17(0.12)$ & $0.10(0.23)$ & $0.066^{a}$ \\
\hline
\end{tabular}

$p$-Values $<0.05$ were considered statistically significant. ${ }^{\mathrm{a}} p$-Value determined by a independent samples $t$-test, moderate vs. severe stroke; ${ }^{\mathrm{b}} p$-value determined by a Mann-Whitney $U$ test; ${ }^{c} p$-value determined by a chisquare test or Fisher's exact test, where appropriate; ${ }^{\mathrm{d}}$ FIM efficiency is defined as change between admission and discharge FIM divided by length of service.

moderate to severe functional deficits after inpatient rehabilitation. While the possibility exists that the larger improvements on the FIM seen by moderate/severe stroke patients may be due to a ceiling effect on part of the mild stroke patients, these results nevertheless indicate that CSR may be an effective method to facilitate discharge home and provide continued stroke care for persons still experiencing a moderate to high degree of functional disability after inpatient rehabilitation. Although moderate/severe stroke patients had a longer length of service and a greater number of total visits compared to mild stroke patients, these patients were still on average within the 12-week program target and no
Table 2: Patient and program characteristics of the CSR program, by stroke severity group

\begin{tabular}{|c|c|c|c|}
\hline & $\begin{array}{l}\text { Mild stroke } \\
\qquad(\mathbf{n}=\mathbf{5 3})\end{array}$ & $\begin{array}{c}\text { Moderate/ } \\
\text { severe stroke } \\
\quad(\mathbf{n}=\mathbf{2 0})\end{array}$ & $p$-Value \\
\hline Age, mean (SD) & $74.3(11.8)$ & $72.7(13.48)$ & $0.617^{\mathrm{a}}$ \\
\hline Age, median (IQR) & $75.5(69-83.8)$ & $74(65.3-81.5)$ & $0.628^{\mathrm{b}}$ \\
\hline \multicolumn{4}{|l|}{ Sex, $n(\%)$} \\
\hline Male & $28(53 \%)$ & $10(50 \%)$ & $0.829^{\mathrm{c}}$ \\
\hline Female & $25(47 \%)$ & $10(50 \%)$ & \\
\hline \multicolumn{4}{|l|}{ Residence, $n(\%)$} \\
\hline Windsor & $37(70 \%)$ & $13(65 \%)$ & $0.693^{\mathrm{c}}$ \\
\hline County & $16(30 \%)$ & $7(35 \%)$ & \\
\hline $\begin{array}{l}\text { FIM efficiency }{ }^{\mathrm{d}} \text { in inpatient } \\
\text { rehabilitation, mean }(\mathrm{SD})\end{array}$ & $1.2(0.76)$ & $0.55(0.54)$ & $<0.001^{\mathrm{a}}$ \\
\hline \multicolumn{4}{|l|}{$\begin{array}{l}\text { Number of CRS visits, } \\
\text { mean (SD) }\end{array}$} \\
\hline Total & $35.6(12.97)$ & $48.8(16.51)$ & $0.004^{\mathrm{a}}$ \\
\hline Physiotherapist & $6.1(3.84)$ & $9.6(4.73)$ & $0.003^{\mathrm{a}}$ \\
\hline Occupational therapist & $6.8(2.97)$ & $8.0(2.88)$ & $0.208^{\mathrm{a}}$ \\
\hline $\begin{array}{l}\text { Speech language } \\
\text { pathologist }\end{array}$ & $5.0(7.16)$ & $9.6(7.34)$ & $0.031^{\mathrm{a}}$ \\
\hline Certified Rehab. assistant & $13.3(6.10)$ & $17.3(7.63)$ & $0.060^{\mathrm{a}}$ \\
\hline Registered nurse & $1.9(1.12)$ & $2.1(.99)$ & $0.524^{\mathrm{a}}$ \\
\hline Social worker & $2.6(1.38)$ & $2.3(1.15)$ & $0.368^{\mathrm{a}}$ \\
\hline $\begin{array}{l}\text { Length of service (days), } \\
\text { mean (SD) }\end{array}$ & $71.4(18.46)$ & $84.6(12.43)$ & $0.106^{\mathrm{a}}$ \\
\hline $\begin{array}{l}\text { Resource intensity (visits } \\
\text { per week), mean (SD) }\end{array}$ & $3.6(1.36)$ & $4.0(1.10)$ & $0.274^{\mathrm{a}}$ \\
\hline Admission FIM, mean (SD) & $101.3(10.16)$ & $58.4(16.96)$ & $<0.001^{\mathrm{a}}$ \\
\hline Discharge FIM, mean (SD) & $111.7(8.81)$ & $74.7(21.64)$ & $<0.001^{\mathrm{a}}$ \\
\hline $\begin{array}{l}\text { FIM efficiency }{ }^{\mathrm{d}} \text { in CSR } \\
\text { program, mean (SD) }\end{array}$ & $0.16(0.11)$ & $0.20(0.14)$ & $0.209^{\mathrm{a}}$ \\
\hline
\end{tabular}

Excludes stroke patients who were discharged early in order to transition to hospital outpatient rehabilitation program $(n=22)$. $p$-Values $<0.05$ were considered statistically significant. ${ }^{a} p$-Value determined by a independent samples $t$-test, moderate vs. severe stroke; ${ }^{\mathrm{b}} p$-value determined by a Mann-Whitney $U$ test; ${ }^{\mathrm{c}} p$-value determined by a chi-square test; ${ }^{\mathrm{d}}$ FIM efficiency is defined as change between admission and discharge FIM divided by length of service.

significant differences in resource intensity were identified suggesting that resource utilization was similar between groups.

It should be noted that these data were collected primarily for clinical purposes with multiple clinicians, inherent limitations exist with the accuracy of the data, and should be considered when interpreting results. Furthermore, these results are still preliminary and follow-up data are currently being collected to determine the long-term benefits of CSR for stroke patients in WEC, including an assessment of program cost and the logistical challenges associated with delivery. However, these preliminary results are a positive indication of the effectiveness of CSR for a range of stroke patients and may be considered by other CSR teams when assessing the suitability of program patients and conducting discharge planning for their programs. 


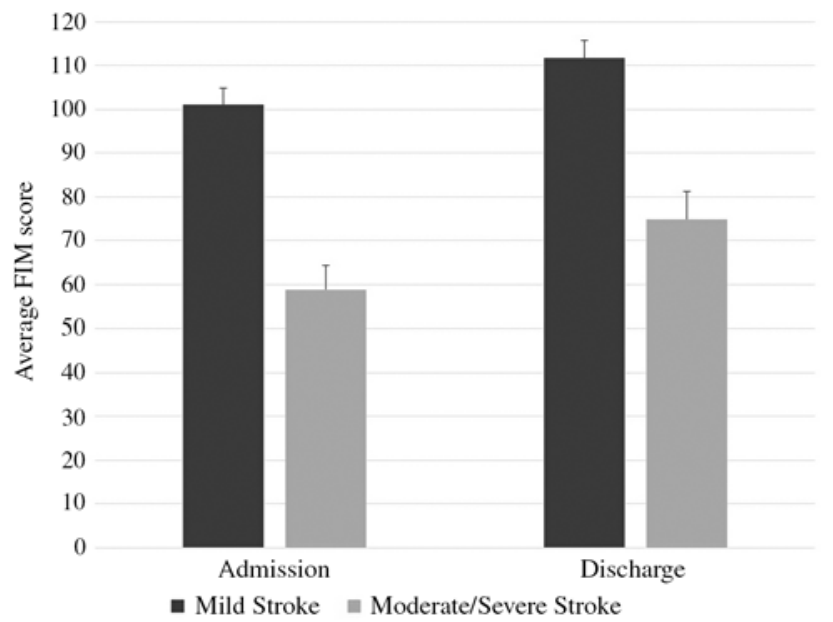

Figure 1: Interaction between stroke severity and functional improvement from admission to discharge from the CSR program, after adjusting for age and resource intensity, $p=0.020$.

\section{Disclosures}

The authors have no conflicts of interest to disclose.

\section{Statement of Authorship}

All authors made substantive contributions to the manuscript, including participation in the conception and design of the work reported in the manuscript (JP, SB, SM, \& MJ), data analysis and interpretation (JV, MM, JP, \& NRL), and drafting the manuscript (JV \& MM). All authors contributed equally in providing critical revision, editing, and final approval of the manuscript.

\section{REFERENCES}

1. Hebert D, Lindsay MP, McIntyre A, et al. Canadian stroke best practice recommendations: stroke rehabilitation practice guidelines, update 2015. Int J Stroke. 2016;11:459-84.

2. Langstaff C, Martin C, Brown G, et al. Enhancing community-based rehabilitation for stroke survivors: creating a discharge link. Top Stroke Rehabil. 2014;21:510-9.

3. Passalent LA, Landry MD, Cott CA. Wait times for publically funded outpatient and community physiotherapy and occupational therapy services: implications for the increasing number of persons with chronic conditions in Ontario, Canada. Physiother Can. 2009;61:5-14.

4. Pereira S, Foley N, Salter K, et al. Discharge destination of individuals with severe stroke undergoing rehabilitation: a predicative model. Disabil Rehabil. 2014;36(6):727-31.

5. Pereira S, Ross Graham J, Shahabaz A, et al. Rehablitation of individuals with severe stroke: Synthesis of best evidence and challenges in implementation. Topics Stroke Rehabil. 2012;19:122-31.

6. Windsor Essex County Health Unit. Community needs assessment report. Windsor, Ontario; 2016.

7. Hall RE, Kahn F, Levi J, et al. Ontario and LHIN 2015/2016 stroke report cards and progress reports: setting the bar higher. Toronto, ON: Institute for Clinical Evaluative Science; 2017.

8. Allen L, Richardson A, McIntyre S, et al. Community stroke rehabilitation teams: providing home-based stroke rehabilitation in Ontario, Canada. Can J Neurol Sci. 2014;41:697-703.

9. Allen L, McIntyre A, Janzen S, et al. Community stroke rehabilitation: how do rural residents fare compared with their urban counterparts? Can J Neurol Sci. 2016;43:98-104.

10. Canadian Institute for Health Information. Pathways of care for people with stroke in Ontario; 2012. Available at: https://secure. cihi.ca/estore/productFamily.htm?locale $=$ en\&pf $=$ PFC1695.

11. Keith RA, Granger CV, Hamilton BB, et al. The functional independence measure: a new tool for rehabilitation. Adv Clin Rehabil. 1987;1:6-18.

12. Teasell R, Hussein N, Foley N. Evidence-based review of stroke rehabilitation (EBRSR), 18th ed. London, ON; EBRSR: 2018. Available at: https://www.ebrsr.com. 